\title{
THE DOSE-RESPONSE RELATIONSHIP BETWEEN INFLUENZA VIRUSES AND THE SURVIVING ALLANTOIS
}

\author{
By S. FAZEKAS DE ST GROTH AND D. O. WHITE* \\ The Department of Microbiology, The John Curtin School of Medical Research, \\ Australian National University, Canberra, Australia
}

(With 2 Figures in the Text)

\section{INTRODUCTION}

While a number of tissues will serve as host for the multiplication of influenza viruses, none yet known is uniformly susceptible to infection. The variation from host to host lowers the accuracy of assays, but this is of no great moment as the loss can be made good in practice by doing a larger number of tests. The challenging aspect is the existence, side by side, in a set of seemingly identical host organisms of some highly susceptible to infection and others naturally resistant.

It was with this phenomenon in mind that we set out to improve the method of Fulton \& Armitage (1951), $\dagger$ so that it might afford experimental means for the study of the nature and distribution of host-resistance to infection. Once the allantoic lining of the developing chick, the most commonly used host system for influenza viruses, can be divided into small fragments and maintained in vitro without loss of susceptibility, the way is open to alter environmental conditions at will and observe their effect on the response of the tissue. The first stage of this work was to define the basic dose-response relationship against which natural and experimental variation may then be evaluated. In the present paper therefore we shall deal with the infective behaviour of ten influenza strains maintained under optimal conditions in surviving bits of the allantois.

All materials, as well as our method of growing influenza viruses in surviving bits of the allantois, have been fully described in the first paper of this series (Fazekas de St Groth \& White, 1958a); the ten strains of influenza virus are the same as used in an earlier study (Fazekas de St Groth \& Graham, 1954).

\section{EXPERIMENTS}

Variation within eggs

Susceptibility to infection. The first set of experiments served to determine whether or not different regions of the allantois were equally infectible. Since systematic variation is most likely to occur along the axial gradients of development, squares of membrane-on-shell were collected from five zones of each egg: the

* Present address: Bacteriology Department, University of Melbourne, Melbourne, Australia.

$\dagger$ In a recent paper Finter \& Armitage (1957) have modified this technique by cutting the chorio-allantois while still adhering to the shell, but the sensitivity of their method was little improvement on that of Fulton \& Armitage. 
albumen end, the albumen third, the centre, the airspace third and the airspace end. Bits from 24 eggs were distributed in separate plastic trays containing $0.30 \mathrm{ml}$. of Standard Medium (SM) per cup. A series of twofold dilutions of the BEL (A) strain was used as infective inoculum, and the test was read after $48 \mathrm{hr}$. incubation at $36^{\circ} \mathrm{C}$. The titres were worked out by the simplified computation (Fazekas de St Groth, 1955) based on the method of Reed \& Muench (1938). Table 1 gives the results.

Clearly, the mean infectivity titres of the five groups are statistically indistinguishable. The same conclusion was reached by an analysis of variance where, after elimination of any effect the difference between eggs might have contributed, we obtained the variance ratio of 1.40 with 4 and 92 degrees of freedom. Such a value would occur purely by chance once in every four trials.

Whereas these results suggest that the average susceptibility of bits does not vary from one region to another, they do not answer the more stringent question whether the probability of infection is the same for every single piece. Since any deviation from uniformity will flatten the dose-response curve (Moran, 1954a)

Table 1. Susceptibility to infection of different regions of the allantois

\begin{tabular}{lccc}
\multicolumn{1}{c}{ Region } & Infectivity titre \pm standard erro \\
Albumen end & $\mathbf{7 \cdot 7 8}$ & \pm & $\mathbf{0 . 1 4}$ \\
Albumen third & $\mathbf{7 . 9 2}$ & \pm & $0 \cdot 18$ \\
Centre & $\mathbf{7 . 9 2}$ & \pm & $\mathbf{0 \cdot 1 6}$ \\
Airspace third & $\mathbf{7 . 8 9}$ & \pm & $0 \cdot 20$ \\
Airspace end & $\mathbf{7 . 8 5}$ & \pm & $\mathbf{0 . 2 0}$ \\
$\quad$ Mean & $\mathbf{7 . 8 7}$ & \pm & 0.077
\end{tabular}

Each of the titres, given in $\log _{10}$ units $/ 0.025 \mathrm{ml}$, is based on replicates from twenty-four eggs.

variations of this kind may be detected and evaluated by appropriate statistical tests. The elegant method of Moran $(1954 a, b)$ was designed for this particular purpose, and found to be more powerful than other parametric methods (Armitage \& Spicer, 1956). We applied Moran's test to infectivity titrations on the BEL strain, done during the development of the technique (Fazekas de St Groth \& White, $1958 a$ ), as well as to further tests performed on nine other strains of influenza virus in a comparative study of the intact and surviving allantois (Fazekas de St Groth \& White, 1958c).

The results of Table 2, based on a large volume of experimental material, suggest no significant differences in susceptibility between bits of allantois-onshell derived from any one egg. This holds for all ten strains of influenza virus tested.

The yield of haemagglutinating virus. It does not follow from their uniform response to infective virus that bits derived from the same egg will behave uniformly when tested by other criteria of virus action. Indeed, equal susceptibility to infection, as demonstrated in the previous section, shows only the absence of gross qualitative differences within eggs. In the next set of experiments therefore we looked for quantitative variation, and chose to base our comparisons on the final stage of the intracellular cycle, namely the number of virus particles produced by 
a standard area of the allantois, and the rate at which these are released from cells. Both can be tested in the same experiment if a nearly saturating dose of virus is used as infective inoculum, and the medium is sampled near the peak of the first cycle of multiplication, and then again when the titres have reached their maximum. The comparison of regions was made on the same material as used above for infectivity tests. The medium was sampled 7 and $24 \mathrm{hr}$. after infection with about $10^{6} \mathrm{ID}_{50}$ of $\mathrm{BEL}$ virus (Table 3 ).

As in the case of susceptibility to infection, the regional differences within any one egg were insignificant, as regards both the rate of production and final yields.

Table 2. Distribution of susceptibility to infection within 11-day eggs

Strain M-values

$\begin{array}{llcr}\quad \text { Strain } & \text { M-values } & \overline{\mathbf{M}} \\ \text { WSE (A) } & -1 \cdot 4,-1 \cdot 4,-0 \cdot 7,-0 \cdot 4,0 \cdot 0,0 \cdot 0,+0 \cdot 4,+0 \cdot 4,+0 \cdot 4,+0 \cdot 7,+0 \cdot 7,+1 \cdot 0 & +0 \cdot 03 \\ \text { PR 8 (A) } & -2 \cdot 1,-1 \cdot 4,-1 \cdot 0,-1 \cdot 0,-0 \cdot 7,-0 \cdot 7,-0 \cdot 4,0 \cdot 0,+0 \cdot 4,+0 \cdot 7,+0 \cdot 7,+1 \cdot 4 & -0 \cdot 38 \\ \text { MEL (A) } & -2 \cdot 4,-1 \cdot 8,-1 \cdot 8,-0 \cdot 4,0 \cdot 0,0 \cdot 0,+0 \cdot 4,+0 \cdot 4,+0 \cdot 7,+0 \cdot 7,+1 \cdot 4,+1 \cdot 8 & -0 \cdot 09 \\ \text { BEL (A) } & -1 \cdot 4,-1 \cdot 0,-0 \cdot 7,-0 \cdot 7,-0 \cdot 4,-0 \cdot 4,0 \cdot 0,0 \cdot 0,0 \cdot 0,+0 \cdot 7,+0 \cdot 7,+1 \cdot 0 & -0 \cdot 18 \\ \text { JAM (A') } & -2 \cdot 8,-2 \cdot 4,-2 \cdot 1,-1 \cdot 8,-0 \cdot 7,-0 \cdot 4,0 \cdot 0,+0 \cdot 4,+0 \cdot 7,+0 \cdot 7,+1 \cdot 0,+1 \cdot 8 & -0 \cdot 38 \\ \text { FM 1 (A') } & -1 \cdot 0,-1 \cdot 0,-0 \cdot 7,-0 \cdot 4,-0 \cdot 4,-0 \cdot 4,0 \cdot 0,+0 \cdot 4,+0 \cdot 4,+0 \cdot 7,+0 \cdot 7,+1 \cdot 0 & -0 \cdot 06 \\ \text { LEE (B) } & -2 \cdot 1,-0 \cdot 7,-0 \cdot 7,-0 \cdot 4,-0 \cdot 4,-0 \cdot 4,-0 \cdot 2,+0 \cdot 1,+0 \cdot 4,+0 \cdot 7,+0 \cdot 9,+1 \cdot 0 & -0 \cdot 10 \\ \text { BON (B) } & -1 \cdot 8,-1 \cdot 4,-1 \cdot 0,-0 \cdot 4,-0 \cdot 4,0 \cdot 0,+0 \cdot 7,+0 \cdot 7,+1 \cdot 0,+1 \cdot 4,+1 \cdot 4,+1 \cdot 4 & +0 \cdot 15 \\ \text { HUT (B) } & -1 \cdot 0,-0 \cdot 4,-0 \cdot 4,-0 \cdot 4,0 \cdot 0,0 \cdot 0,+0 \cdot 4,+0 \cdot 4,+0 \cdot 4,+0 \cdot 4,+0 \cdot 7,+1 \cdot 0 & +0 \cdot 09 \\ \text { SW (S) } & -1 \cdot 4,-1 \cdot 0,-0 \cdot 7,-0 \cdot 7,-0 \cdot 4,-0 \cdot 4,-0 \cdot 4,0 \cdot 0,+0 \cdot 4,+0 \cdot 7,+0 \cdot 7,+0 \cdot 7 & -0 \cdot 20\end{array}$

Each of the M-values (Moran, 1954a, $b$ ) is based on infectivity tests performed on bits of 11-day eggs with twofold dilutions of the test viruses and five replicates per dilution.

Table 3. Yield of haemagglutinating virus from different regions of the allantois

\begin{tabular}{lcc} 
& \multicolumn{2}{c}{ Yield } \\
\cline { 2 - 3 } \multicolumn{1}{c}{ Region } & At $7 \mathrm{hr}$. & At $24 \mathrm{hr}$. \\
Alburmen end & $1.23 \pm 0.06$ & $2.30 \pm 0.06$ \\
Albumen third & $1.11 \pm 0.08$ & $2 \cdot 21 \pm 0.10$ \\
Centre & $1.19 \pm 0.06$ & $2 \cdot 21 \pm 0.09$ \\
Airspace third & $1.18 \pm 0.05$ & $2 \cdot 18 \pm 0.06$ \\
Airspace end & $1.08 \pm 0.05$ & $2.17 \pm 0.08$ \\
$\quad$ Mean & $1 \cdot 160 \pm 0.028$ & $2.211 \pm 0.037$
\end{tabular}

The yields \pm standard errors are given in $\log _{10}$ units; each is based on twenty replicates.

Similar experiments were done on strains WSE, PR 8, CAM and SW. The findings were consistently negative, that is, no variation in yields beyond that due to chance could be detected when bits from the same egg were compared. Since these particular experiments also tested inter-egg variation, they will be dealt with in detail under that heading. Hereafter, bits from all regions of the allantois of a single egg were assumed to behave in the same way, and were used indiscriminately.

\section{Variation between eggs}

The early hope that bits coming from one egg would behave uniformly was fulfilled by the findings of the previous sections. The magnitude and nature of variation between eggs remained to be determined. Once again, susceptibility to infection and final yield of virus particles were treated separately, but the tests were done 
on material from the same eggs, so that, should significant variation be found, the proper analysis of correlation between the two aspects of virus-host interaction could be performed.

Susceptibility to infection. Experiments under this heading were usually done on groups of ten to twenty eggs per strain of virus, i.e. on about 400-800 units of host tissue. The bits coming from each egg were distributed orthogonally over the trays, giving up to twenty independent inter-egg comparisons with five replicate rows per egg. Due to the systematic arrangement of host tissue, the variation between eggs could be estimated separately and compared with the appropriate

Table 4. Variation of susceptibility to infection between bits of allantois-on-shell

\begin{tabular}{|c|c|c|c|c|c|}
\hline \multirow[b]{2}{*}{ Strain } & \multirow{2}{*}{$\begin{array}{l}\text { Source of variation } \\
\text { and } \\
\text { (degrees of freedom) }\end{array}$} & \multirow{2}{*}{$\begin{array}{c}\text { Mean } \\
\text { square }\end{array}$} & \multirow{2}{*}{$\begin{array}{l}\text { Variance } \\
\text { ratio }\end{array}$} & \multicolumn{2}{|c|}{ Significance } \\
\hline & & & & Experimental & Theoretical* \\
\hline WSE (A) & $\begin{array}{l}\text { Between (18) } \\
\text { Within (76) }\end{array}$ & $\begin{array}{l}0 \cdot 3774 \\
0 \cdot 1058\end{array}$ & $3 \cdot 57$ & $P<0.001$ & $P<0.001$ \\
\hline $\operatorname{PR} 8$ (A) & $\begin{array}{l}\text { Between (19) } \\
\text { Within (80) }\end{array}$ & $\begin{array}{l}0.5064 \\
0.0999\end{array}$ & $5 \cdot 07$ & $P<0.001$ & $P<0.001$ \\
\hline MEL (A) & $\begin{array}{l}\text { Between (19) } \\
\text { Within (80) }\end{array}$ & $\begin{array}{l}0.1785 \\
0 \cdot 1249\end{array}$ & $1 \cdot 43$ & $P \sim 0.15$ & $P \sim 0.008$ \\
\hline BEL (A) & $\begin{array}{l}\text { Between (15) } \\
\text { Within (64) }\end{array}$ & $\begin{array}{l}0 \cdot 2200 \\
0 \cdot 1266\end{array}$ & $1 \cdot 74$ & $P \sim 0.08$ & $P \sim 0.003$ \\
\hline $\mathrm{CAM}\left(\mathrm{A}^{\prime}\right)$ & $\begin{array}{l}\text { Between (12) } \\
\text { Within (52) }\end{array}$ & $\begin{array}{l}0.5678 \\
0.0912\end{array}$ & $6 \cdot 22$ & $P<0.001$ & $P<0.001$ \\
\hline FM $1\left(A^{\prime}\right)$ & $\begin{array}{l}\text { Between (19) } \\
\text { Within (80) }\end{array}$ & $\begin{array}{l}0.2299 \\
0.1010\end{array}$ & $2 \cdot 28$ & $P \sim 0.01$ & $P<0.001$ \\
\hline LEE (B) & $\begin{array}{l}\text { Between (8) } \\
\text { Within (36) }\end{array}$ & $\begin{array}{l}0.3275 \\
0.0979\end{array}$ & $3 \cdot 35$ & $P \sim 0.007$ & $P<0.001$ \\
\hline BON (B) & $\begin{array}{l}\text { Between (17) } \\
\text { Within (72) }\end{array}$ & $\begin{array}{l}0.7589 \\
0 \cdot 1723\end{array}$ & $4 \cdot 40$ & $P<0.001$ & - \\
\hline HU'T (B) & $\begin{array}{l}\text { Between (13) } \\
\text { Within (56) }\end{array}$ & $\begin{array}{l}0.2616 \\
0.0932\end{array}$ & $2 \cdot 81$ & $P \sim 0.007$ & $P<0.001$ \\
\hline SW (S) & $\begin{array}{l}\text { Between (19) } \\
\text { Within (80) }\end{array}$ & $\begin{array}{l}0.1339 \\
0.0997\end{array}$ & $1 \cdot 34$ & $P \sim 0.20$ & $P \sim 0.07$ \\
\hline
\end{tabular}

experimental error term (namely variation within eggs) and also with the theoretically defined variance of quantal infectivity tests. The infective inoculum came from ampouled seed virus which was stored at $-70^{\circ} \mathrm{C}$. Although this should ensure the uniformity of the challenging inoculum, and thus allow pooling of results obtained on different days, the Tables of this section are based on tests done on the same day, using a single set of dilutions made up from one ampoule of seed virus. This precaution was taken to avoid the confounding of inter-egg variation, which we set out to determine, with possible variation due to other causes such as time, reagents or operators.

Since viruses belonging to type $B$ are characterized by a slower rate of multiplication than A-strains, tests of this set were incubated for $72 \mathrm{hr}$. at $36^{\circ} \mathrm{C}$. after infection. A summary of the analysis of variance computed from the results is given in Table 4. 
Considering the experimental variances first, the results prove that susceptibility to infection varies from egg to egg. In absolute terms this variation is small. If, say, only a hundred bits of host tissue had been used to test each strain of virus, the variance ratios would not have reached even the lowest level of significance $(P=0.05)$ with any of the strains. With the number of test subjects used in our experiment, seven strains are seen to vary significantly; two, MEL and BEL, are placed in the $10 \%$-region; and only for one, SW, could the eggs be said to behave homogeneously.

If the theoretical variance, ${ }^{*} 0 \cdot 09$, is to be used to evaluate inter-egg variation, the first question that must be answered is whether the experimental error (i.e. variation within eggs) is significantly higher than this minimum. The appropriate tests show that in the case of nine strains the observed difference would occur by chance in one quarter or more of all trials $(P \geqslant 0.25)$; with the tenth strain, BON, the variation within bits of the same egg is significantly higher than the theoretical $(P=0.02)$.

The overall experimental variance within eggs is $0 \cdot 1125$, based on 676 degrees of freedom; its ratio to the theoretical minimum would be obtained only in $3 \%$ of the cases by chance, and is therefore just significant. Again, it is the BON strain which contributes overwhelmingly to this result. If only the other nine strains are considered, the pooled variance becomes $0 \cdot 1054$, with 604 degrees of freedom; the variance ratio so obtained is not significant $(P \sim 0 \cdot 16)$.

Thus, at least for the nine strains whose response curve within any one egg does not differ from the theoretical, the distribution of susceptibility between eggs may be assessed against the theoretical variance. Since the latter has an infinite number of degrees of freedom, the probabilities listed in the last column of Table 4 were derived from $\chi^{2}$-tests rather than the less extensively tabulated variance ratios. MEL and BEL now become significant, and SW so close to the conventional level

* The variance of quantal dilution assays is

$$
V=d^{2} \Sigma \frac{p_{i} \cdot q_{i}}{n_{i}},
$$

where $d$ is the log dilution step, $n_{i}$ the number of subjects tested at level $i$, and $p_{i}, q_{i}$ the expected proportion responding or failing to respond at that level. An unbiassed estimator of $V$ is

$$
s^{2}=d^{2} \Sigma\left(\frac{r_{i}}{n_{i}}\right)\left(\frac{n_{i}-r_{i}}{n_{i}}\right)\left(\frac{1}{n_{i}-1}\right),
$$

where $r_{i}$ is the observed number of responses out of $n_{i}$. (This formula ignores the contribution of the periodic component (Irwin, 1937), which is for all practical purposes negligible at closely spaced doses and small $n$.) If the number of subjects is the same at each level, eq. 2 may be written

$$
s^{2}=\frac{d^{2}}{n} \cdot \frac{\Sigma\left[r_{i}\left(n-r_{i}\right)\right]}{n(n-1)} .
$$

Now, for tests where the proportion of non-responders is given by the zero term of the Poisson distribution, the second part of the numerator in eq. 3 equals Moran's statistic $T$. In the case of twofold dilutions the expectation of $T$ is $n(n-1)$, and hence for this particular case the variance formula reduces to $d^{2} / n$. Thus, in $\log _{10}$ units, the theoretical variance of a test in a single row of twofold dilutions is 0.09 . This value has been used to calculate the last column of Table 4. 
of significance that the whole set of strains may be taken to show some variation between eggs.

With the finding of these small but consistent differences in the susceptibility of eggs, it was of interest to determine whether an egg which showed a certain degree of resistance to infection by a particular virus would react in the same way to other strains. The answer to this question was sought in the following experiment. Several eggs were cut into eighty bits each, and forty of these were used in an infectivity test with one strain of virus, forty with another. The pairs CAM-LEE and BON-HUT were compared in such tests. The observed correlation coefficients, +0.717 and +0.685 , are based on 24 and 20 degrees of freedom respectively. Both are highly significant $(P<0.001)$, and show that the distribution of susceptibility does not depend on the virus used in the test, but is a characteristic of the eggs alone.

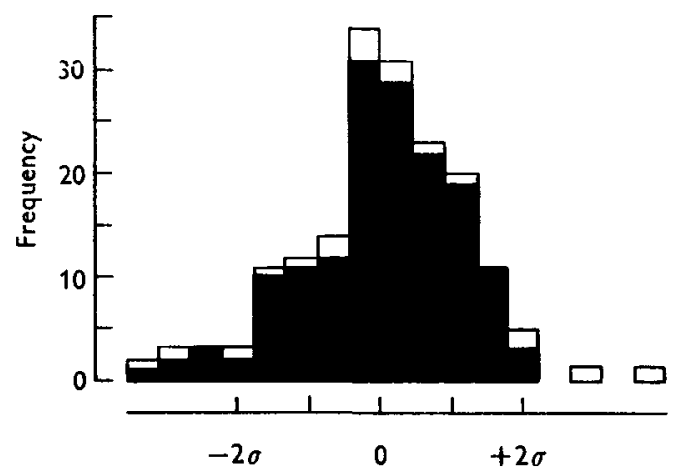

Fig. 1. Variation of susceptibility between eggs. (The histogram shows the distribution of $\log$ infectivity titres about their common mean. The tests were done on bits of allantoison-shell from 169 eggs. The black columns represent strains WSE, PR 8, MEL, BEL, CAM, FM 1, LEE, HUT and SW; the white columns show the behaviour of the slightly aberrant BON strain. Each column contains infectivity titres covering a range of $0 \cdot 10$ $\log _{10}$ units.)

This demonstration, taken together with the fact that-excepting BON-the variation about the mean level of infectivity is the same for all strains, allows the pooling of observations and the plotting of a common distribution of host resistance between eggs. Indeed, in absolute value, the variance associated with the BON strain hardly differs from the others, and therefore the histogram of Fig. 1 shows the distribution of susceptibility for the homoscedastic group in black, with the frequencies found for BON superimposed in white.

The normal curve has been fitted to the observed frequencies at $0 \cdot 10 \log _{10}$ (i.e. $0 \cdot 44 \sigma$ ) intervals, as shown in Fig. 1. The small frequencies at the tail ends were pooled to give minimum totals of 5 . According to the results the distribution of susceptibility between eggs does not differ from the normal $\left(\chi_{(7)}^{2}=8 \cdot 17 ; P \sim 0 \cdot 35\right)$, and the apparent negative skewness is not significant. If the BON strain is included in the distribution, the fit becomes rather worse.

So far the experiments were designed to give the most informative comparisons of variation within and between eggs. And the span of challenging doses was 
chosen with an eye on the M-test, that is, to cover the whole range of responses from all positive to all negative. With the finding of small differences between eggs we wished to assess the significance of these independently and, if possible, more accurately. The appropriate design here ignores the tails of the dose-response curve and allocates correspondingly larger numbers of test subjects to groups which give the most information. In response curves based on the Poisson distribution this region lies in the range of doses giving between 60 and $90 \%$ 'takes'. In the next experiment therefore only three doses of virus were used, in steps twofold apart. Each of these was inoculated into 180 cups containing bits from twelve eggs. The results were analysed by the maximum likelihood fitting of the negative exponential.

The data of Table 5 were obtained with the BEL strain, one of the three which failed to show inter-egg variation on the internal evidence of the smaller experiments described above. Here, by increasing the number of replicates per level to

Table 5. Variation of susceptibility between eggs

The figures show the number of infected bits of membrane-on-shell out of a total of fifteen.

\begin{tabular}{|c|c|c|c|c|c|c|c|c|c|c|c|c|c|}
\hline \multirow{2}{*}{$\begin{array}{c}\text { Dilution } \\
\left(\log _{10}\right)\end{array}$} & \multicolumn{12}{|c|}{ Egg } & \multirow[b]{2}{*}{ Total } \\
\hline & 1 & 2 & 3 & 4 & 5 & 6 & 7 & 8 & 9 & 10 & 11 & 12 & \\
\hline $7 \cdot 42$ & 15 & 12 & 13 & 15 & 11 & 15 & 15 & 15 & 14 & 12 & 15 & 15 & 167 \\
\hline $7 \cdot 72$ & 8 & 10 & 14 & 15 & 5 & 13 & 11 & 15 & 13 & 11 & 11 & 14 & 140 \\
\hline 8.02 & 6 & 9 & 10 & 12 & 3 & 6 & 7 & 10 & 10 & 10 & 10 & 6 & 99 \\
\hline \multicolumn{14}{|c|}{ Analysis of variance } \\
\hline \multicolumn{4}{|c|}{ Source of variation } & \multicolumn{4}{|c|}{$\begin{array}{l}\text { Degrees of } \\
\text { freedom }\end{array}$} & \multicolumn{2}{|c|}{$\begin{array}{l}\text { Mean } \\
\text { square }\end{array}$} & \multicolumn{3}{|c|}{$\begin{array}{c}\text { Variance } \\
\text { ratio }\end{array}$} & Significance \\
\hline \multicolumn{4}{|c|}{ Between eggs } & \multirow{2}{*}{\multicolumn{4}{|c|}{11}} & 0.49 & & \multirow{2}{*}{\multicolumn{3}{|c|}{$10 \cdot 72$}} & $P<0.001$ \\
\hline \multicolumn{3}{|c|}{ Within eggs } & & & & & & \multicolumn{2}{|c|}{0.0459} & & & & \\
\hline
\end{tabular}

fifteen and by restricting the range of doses to the region of maximum information, the evidence for variation between eggs becomes unequivocal.

The same conclusion is reached when the slopes of the log log curves (Mather, 1949) are examined. The estimated slopes for each of the twelve eggs were compatible with the slope defined by the Poisson distribution, that is, there was no sign of inhomogeneity among tissue derived from any one egg. The overall slope, on the other hand, was found to be significantly flatter.

The yield of haemagglutinating virus. These tests were done on the same eggs which have already served for the comparison of host-resistance to infection (see Table 4). Five carefully marked squares of allantois-on-shell were cut from each, and infected with about $10^{4} \mathrm{ID}_{50}$ of one of the viruses. After $24 \mathrm{hr}$. incubation the medium was removed and tested for haemagglutinin against fowl red cells. Although in the actual titrations twofold dilutions were used, and hence the results read in $\log _{2}$ units, the entries of both Table 6 and Fig. 2 have been transformed to $\log _{10}$ units. Thus the variances of the two kinds of test (infectivity and haemagglutinin) are directly comparable, and the distributions are plotted on the same scale. 
Unlike in the assay of infectivity, where the inherent limitations of the method set an upper bound to the accuracy, the error of haemagglutinin titrations is relatively small and affords a more powerful criterion for the evaluation of egg-toegg variation. For this reason the answer is clear-cut: the eggs are seen to vary significantly, all variance ratios being well beyond the $0.1 \%$ level of probability (Table 6). Just as an egg's resistance to infection does not depend primarily on the strain of virus used, so it was found that the yield of haemagglutinin was equally independent.

When the variances of all strains were compared, BON once again occupied a position apart from the other nine. In this instance, however, the discrepancy was

Table 6. Variation of virus yield between bits of allantois-on-shell

\begin{tabular}{|c|c|c|c|c|}
\hline Strain & $\begin{array}{l}\text { Source of variation } \\
\text { and } \\
\text { (degrees of freedom) }\end{array}$ & $\begin{array}{c}\text { Mean } \\
\text { square }\end{array}$ & $\begin{array}{l}\text { Variance } \\
\text { ratio }\end{array}$ & Significance \\
\hline WSE (A) & $\begin{array}{l}\text { Between (18) } \\
\text { Within (76) }\end{array}$ & $\begin{array}{l}0.3315 \\
0.0375\end{array}$ & $8 \cdot 85$ & $P<0.001$ \\
\hline PR 8 (A) & $\begin{array}{l}\text { Between (19) } \\
\text { Within (80) }\end{array}$ & $\begin{array}{l}0.1448 \\
0.0075\end{array}$ & $19 \cdot 32$ & $P<0.001$ \\
\hline MEL (A) & $\begin{array}{l}\text { Between (19) } \\
\text { Within (80) }\end{array}$ & $\begin{array}{l}0.1292 \\
0.0346\end{array}$ & $3 \cdot 73$ & $P<0.001$ \\
\hline BEL (A) & $\begin{array}{l}\text { Between (11) } \\
\text { Within (48) }\end{array}$ & $\begin{array}{l}0 \cdot 1418 \\
0 \cdot 0066\end{array}$ & $21 \cdot 42$ & $P<0.001$ \\
\hline $\mathrm{CAM}\left(\mathrm{A}^{\prime}\right)$ & $\begin{array}{l}\text { Between (12) } \\
\text { Within (52) }\end{array}$ & $\begin{array}{l}0 \cdot 2562 \\
0 \cdot 0300\end{array}$ & $8 \cdot 55$ & $P<0.001$ \\
\hline LEE (B) & $\begin{array}{l}\text { Between (8) } \\
\text { Within (36) }\end{array}$ & $\begin{array}{l}0 \cdot 2183 \\
0 \cdot 0279\end{array}$ & $7 \cdot 81$ & $P<0.001$ \\
\hline BON (B) & $\begin{array}{l}\text { Between (17) } \\
\text { Within (72) }\end{array}$ & $\begin{array}{l}1 \cdot 6003 \\
0 \cdot 0452\end{array}$ & $35 \cdot 42$ & $P<0.001$ \\
\hline HUT (B) & $\begin{array}{l}\text { Between (13) } \\
\text { Within (56) }\end{array}$ & $\begin{array}{l}0 \cdot 1417 \\
0 \cdot 0271\end{array}$ & $5 \cdot 22$ & $P<0.001$ \\
\hline SW (S) & $\begin{array}{l}\text { Between (19) } \\
\text { Within (80) }\end{array}$ & $\begin{array}{l}0 \cdot 1834 \\
0 \cdot 0135\end{array}$ & $13 \cdot 54$ & $P<0.001$ \\
\hline
\end{tabular}

so marked ( $\chi^{2}$ in Bartlett's test including BON 59.29, $P<0 \cdot 001$; without BON 6.92, $P \sim 0.5)$ that we had to omit this strain when the distribution of haemagglutinin yields was plotted in Fig. 2.

It can be seen that the scatter is smaller than in Fig. 1, that is, haemagglutinin yields vary less from egg to egg than does susceptibility to infection. The data are well fitted by the normal curve $\left(\chi_{(5)}^{2}=4 \cdot 48\right)$.

Correlation between susceptibility and yield of virus. Since both infectibility and the number of virus particles produced per unit area were found to vary from egg to egg, it became mandatory to find out whether these two manifestations of virus-cell interaction were linked or not. To this end the relevant data, examined separately above, were combined in an analysis of covariance. The results, best summarized by the correlation coefficients (Table 7), show that variation in susceptibility is independent of variation in virus yield. This is evident both at the 
level of individual strains and in the pooled estimate of correlation, neither of which even approaches significance.

\section{The accuracy of infectivity tests}

The mere fact that such extensive tests as the above were needed to demonstrate significant variation in the behaviour of the host system would indicate that the accuracy of the tests is not much below the theoretical maximum attainable in quantal assays of infectivity. If the overall variance for a single row of twofold dilutions is calculated from Table 4, it comes to $0 \cdot 158$ in $\log _{10}$ units. Exclusion
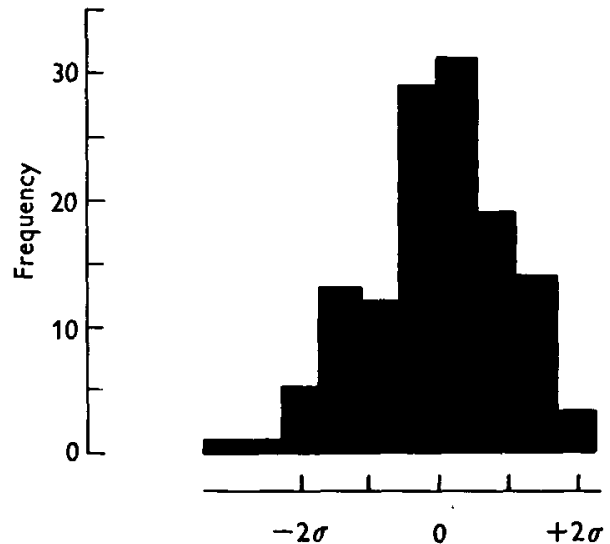

Fig. 2. Variation of yield between eggs. (The histogram shows the distribution of log haemagglutinin titres about their common mean. The tests were done on bits of allantois-onshell from 145 eggs. The strains tested were WSE, PR 8, MEL, BEL, CAM, FM 1, LEE, HUT and SW. Each column contains haemagglutinin yields covering a range of $0 \cdot 10$ $\log _{10}$ units.)

Table 7. Correlation between susceptibility and yield of virus

\begin{tabular}{|c|c|c|}
\hline Strain & $\begin{array}{c}\text { Number of } \\
\text { tests }\end{array}$ & $\begin{array}{c}\text { Correlation } \\
\text { coefficient }\end{array}$ \\
\hline WSE & 19 & +0.05 \\
\hline PR 8 & 20 & +0.20 \\
\hline MEL & 20 & $0 \cdot 00$ \\
\hline BEL & 12 & +0.33 \\
\hline CAM & 13 & $-0 \cdot 15$ \\
\hline LEE & 9 & $+0 \cdot 22$ \\
\hline $\mathrm{BON}$ & 18 & +0.33 \\
\hline HU'T & 14 & +0.28 \\
\hline SW & 16 & -0.50 \\
\hline & & +0.078 \\
\hline
\end{tabular}

of the aberrant BON strain would lower this value by only about $10 \%$ (to $0 \cdot 143$ ); we have adopted the higher figure as an estimate of experimental variation. The standard error of a test with $n$ replicate bits per dilution is given by the familiar formula $\sqrt{(0 \cdot 158 / n)}$. If $d$-fold instead of twofold dilutions are used, the error will be approximately $\sqrt{ }(d / 2)$ times the above.

This basic error is increased if separate sets of dilutions are made up and tested in parallel, or if tests are performed by different operators, or at different times. 
Several experiments were run to check the contribution of these factors, and it was found that in the hands of reasonably trained workers the additional variation did not amount to much. Numerically, the increase of the variance due to different reagents, operators or times of performance came to $0.019,0.000$ and 0.017 respectively. Thus while the basic error in a test with, say, eight replicates per twofold dilution would be $\pm 0 \cdot 140$, it would rise to $\pm 0 \cdot 149$ if different reagents were used, to $\pm 0 \cdot 150$ if also done by different operators, and to $\pm 0 \cdot 156$ if done on different days as well. Under the latter, the least favourable, conditions a difference of $0.43 \log _{10}$ units between end-points would be significant at the $95 \%$ level of confidence. Such tests would use eighty bits of tissue derived from a single egg. Since 118 eggs would be needed to achieve the same accuracy in allantoic infectivity tests, or about sixty mice in intranasal tests-provided the virus is mouse-adapted-the economy of the technique needs little emphasis.

\section{DISCUSSION}

The experimental definition of the dose-response relationship between influenza viruses and the surviving allantois raises three points for discussion. First, the nature of interaction between host and parasite which would lead to an empirical curve like the one observed. Second, ways in which the component mechanisms could be separated and studied independently. And, third, the practical aspects, that is the value and limitations of the technique as a tool in virus research.

The theory of dilution assays, developed largely in response to the demands of bacterial tests, was based on two fundamental assumptions: (1) that the sample is taken at random from a homogeneous population, and (2) that each sample which contains at least one infective unit will register as positive at the time of scoring. If these postulates are fulfilled, the proportion of negative responses is an estimator of the zero term of a Poisson distribution whose mean is the number of infective units per inoculum. If only a fraction of organisms is infective, or if their probability of infection is distributed, the theory still holds. In the latter cases it will estimate the mean infectivity per sample, but the dose-response curve remains Poissonian. Nothing in the experience of bacterial population sampling contradicted this theory - as long as tests were done in vitro. However, in similar tests in animals or, especially, when the theory was applied to viruses, striking discrepancies were observed. The reason is a third postulate implicit in the theory, namely that units of the assay system should be of constant susceptibility. This postulate is automatically fulfilled in the case of synthetic media incubated under controlled conditions; it will hold rarely in living systems of assay, and only under exceptional circumstances in the assay of viruses, where multiplication depends on a more intimate biological interaction of host and parasite.

For an intelligent evaluation of viral infectivity the distribution of host resistance must be known, as it is an integral part of host-virus interaction. Methods have been proposed for the estimation of infectivity even in the absence of such knowledge (Moran, 1955; Armitage \& Spicer, 1956), but they are admittedly no more than statistical makeshifts. The data presented above do not solve the prob- 
lem, although they may be useful in limiting the area of admissible guesses. Armitage \& Spicer have pointed out that Moran's test will detect variation in host resistance only if the average susceptibility is 0.25 or lower, or if its distribution shows extreme positive skewness. Since in practice the M-test demonstrates significant deviations from the Poissonian model (Fazekas de St Groth, 1955), and since the observed distribution (cf. Fig.1) of susceptibility is, if at all, negatively skew, it follows that the average susceptibility must be low. On the other hand, since the ratio of infective to electron microscopically visible virus would fall within the range of $1 / 6$ to $1 / 12$ for the strains we were using (Donald \& Isaacs, 1954), the average susceptibility cannot be lower than 0.08 to 0.15 . This almost amounts to saying that under optimal conditions each visible virus particle is potentially infective, and that the outcome of a virus-cell encounter depends only on the behaviour of the cell. We may go even further and, as there was no detectable variation among bits derived from any one egg, suggest that of the eighteen hypothetical cell-virus interactions considered by Fazekas de St Groth \& Moran (1955), only Hypothesis XII fits the experimental facts. This-eq. 15 of the quoted paper-is a comparatively simple relationship, and should serve as first approximation in the study of natural resistance to virus infection.

The variation from egg to egg is much smaller when the effect is tested on surviving bits. This observation tends to incriminate the medium, since the difference between allantoic fluid and SM may be regarded as the major difference between tests done in vivo and in vitro. It should be mentioned here that on occasion when, due to inadequate rinsing of glassware, traces of detergent found their way into the medium, the infectivity titres dropped by as much as tenfold for some strains and the dose-response curve flattened to a degree found only in tests on whole eggs. There are also other means, some natural and some artificial, of altering host-resistance or enhancing its variability. Since all of these treatments are without any direct effect on the virus, methods for the study of host-resistance may be based on each of them and will be developed in a future paper (White \& Fazekas de St Groth, 1959).

As a method of assay the bits of allantois-on-shell are most naturally compared with the intact allantois of chick embryos. In respect to sensitivity, i.e. the smallest number of virus particles detectable, the two are on the whole equal. At the level of individual strains of influenza virus there are characteristic differences, and these will be evaluated and their mechanism studied in the next paper of this series (Fazekas de St Groth \& White, 1958c). The accuracy of the bit-technique is consistently higher than of allantoic titrations, due to the steeper slope of the doseresponse curve. This statement holds for the comparison of a single square of allantois-on-shell with a whole egg. If the amount of information derived by the two techniques from one egg is considered, the difference is of the order of hundredfold in favour of the surviving tissue. Indeed, although the infectivity test is quantal, its power matches that of quantitative pock- or plaque-counting methods, as the 80-100 units of host tissue will provide a more precise estimate of infective units than do countable numbers of pocks on one membrane or plaques on one layer of cells. 
To date only strains adapted to allantoic growth have been tested in this system, and it is therefore not known whether viruses obtained directly from cases of human influenza would grow equally well or grow at all. Neither is the system fully susceptible to infection by adapted strains: with the exception of one virus (SW), all other strains show lower infectivity than the maximum that could be expected from the number of characteristic particles visible under the electron microscope. Our method shares this shortcoming with all systems of cells known to support the multiplication of influenza viruses, but is perhaps unique in the sense that the two components of virus-cell interaction, the chance of an infective particle being present and the chance that the cell it meets is susceptible, can be studied separately.

\section{SUMMARY}

It is shown that bits of allantois-on-shell cut from any one egg do not differ either in susceptibility to infection by influenza viruses or in yield of haemagglutinin. For this reason the dose-response curve within any egg is Poissonian.

Bits cut from different eggs vary both in susceptibility and in haemagglutinin yield. Unlike in whole eggs however, the scatter is so small that it can be demonstrated only by refined tests done on a large number of subjects. For practical purposes the dose-response curve may still be taken as Poissonian.

Susceptibility and yield vary independently of one another.

The data are used to define the accuracy of infectivity tests in bits of allantoison-shell; the expected errors are given both for straight replication and for tests done with different reagents, by different operators, or at different times.

\section{REFERENCES}

Armttage, P. \& Sptcer, C. C. (1956). J. Hyg., Camb., 54, 401.

Donald, H. B. \& IsaACs, A. (1954). J. gen. Microbiol. 10, 457.

Fazekas de St Groth, S. (1955). J. Hyg., Camb., 53, 276.

Fazekas de St Groth, S. \& Graham, D. M. (1954) . Brit. J. exp. Path. 35, 60.

Fazekas de St Groth, S. \& Moran, P. A. P. (1955). J. Hyg., Camb., 53, 291.

Fazekas de St Groth, S. \& White, D. O. (1958a). J. Hyg., Camb., 56, 151.

Fazekas de St Groth, S. \& White, D. O. (1958c). J. Hyg., Camb., 56, 535.

Finter, N. B. \& Armitage, P. (1957). J. Hyg., Camb., 55, 434.

Fulton, F. \& Armtage, P. (1951). J. Hyg., Camb., 49, 247.

Inwin, J. O. (1937). J. Roy. stat. Soc., Supp. 4, 1.

MATHER, K. (1949). Biometrics, 5, 127.

Moran, P. A. P. (1954a). J. Hyg., Camb., 52, 189.

Moran, P. A. P. (1954b). J. Hyg., Camb., 52, 444.

Moran, P. A. P. (1955). J. Hyg., Camb., 53, 143.

Reed, L. J. \& Muench, H. (1938). Amer. J. Hyg. 27, 493.

White, D. O. \& Fazekas de St Groth, S. (1959). J. Hyg., Camb. (in the Press). 